\title{
Is detection of intraperitoneal exfoliated tumor cells after surgical resection of rectal cancer a prognostic factor of survival?
}

\author{
Christian Arstad $^{1 *}$ (D), Paulo Refinetti ${ }^{2}$, Annette Torgunrud Kristensen ${ }^{1}$, Karl-Erik Giercksky ${ }^{1}$ and Per Olaf Ekstrøm ${ }^{1}$
}

\begin{abstract}
Background: The prognostic significance of free cancer cells detected in peritoneal fluid at the time of rectal surgery remains unclear. A substantial number of patients will develop metastatic disease even with successful local treatment. This prospective non-randomized study investigated the prognostic value of intraperitoneal free cancer cells harvested in peritoneal lavage after surgery for rectal cancer. Mutational hotspots in mitochondrial DNA were examined as potential molecular signatures to detect circulating intraperitoneal free cancer cells when present in primary tumor and in lavage.
\end{abstract}

Methods: Point mutations in mitochondrial DNA amplifications were determined in primary tumors and corresponding exfoliated intraperitoneal free cancer cells in lavage from 191 patients with locally advanced rectal cancer scheduled for radical treatment. Mitochondrial DNA target sequences were amplified by polymerase chain reaction and base substitutions were detected by denaturant, cycling temperature capillary electrophoresis. Detection of intraperitoneal free cancer cells was correlated to survival.

Results: Of 191 patients analyzed, 138 (72\%) were identified with somatic mitochondrial point mutations in rectal cancer tumors. From this fraction, 45 patients (33\%) had positive lavage fluid with corresponding somatic mtDNA point mutations in lavage representing circulating intraperitoneal free cancer cells. There was no significant survival difference between patients identified with or without somatic mitochondrial DNA point mutations in the corresponding lavage.

Conclusion: Somatic mitochondrial DNA point mutations identified in primary rectal tumors enable detection of circulating intraperitoneal free cancer cells in lavage fluid.

Intraperitoneal free cancer cells harvested from lavage immediately after surgery for rectal cancer does not represent an independent prognostic factor on survival.

Keywords: Rectal cancer, Prognostic factor, Survival, mtDNA mutations

\section{Background}

Rectal cancer is frequent in both genders. In 2014 the incidence in Norway was 1365 new cases in a population of 5.05 million citizens. [1]. Randomized studies have demonstrated increased long-term survival in rectal cancer patients receiving chemoradiotherapy in combination with the surgical technique of total mesorectal excision (TME [2]. A substantial number of patients

\footnotetext{
* Correspondence: christian.arstad@medisin.uio.no

'Department of Tumor Biology, Institute for Cancer Research, The Norwegian Radium Hospital, Oslo, Norway

Full list of author information is available at the end of the article
}

develops local recurrence and/or metastatic disease despite successful local treatment $[3,4]$. Detection of intraperitoneal free cancer cells (IPCC) is considered an important prognostic tool in ovarian and gastric cancers [5-11]. In colorectal cancer IPCC with proliferate or metastatic potential may originate from the primary tumor and can possibly be detected by peritoneal lavage [12]. Detection of IPCC during surgery may be of relevance to improve staging and eventually characterize patients who may benefit from aggressive multimodal treatment [12]. However, the clinical significance of detecting IPCC in colorectal cancer is still debated 
[12-15]. Different yield rates $(2,2-31 \%)$ of positive IPCC detection reported in colorectal cancer may be an explanation [12]. Lavage analysis techniques (Cytology, PCR, Immunocytochemistry) used to identify IPCC vary with an average of $13 \%$, as calculated from 11 studies involving more than 100 patients, reviewed by Passot et al. [12]. The use of more sensitive methods to detect IPCC in studies with a large number of patients could determine if IPCC is of clinical relevance.

Somatic mitochondrial DNA (mtDNA) mutations are observed in large fractions of tumors (Manuscript in press). Utilizing somatic mtDNA mutations in the primary tumor can be used as marker to detect IPCC. The axiom is that detection of the same mtDNA mutation in the primary tumor and in the lavage fluid represents IPCC. This study analyses primary tumors and lavage from rectal cancer patients only. The aim of this study was to examine the prognostic impact of IPCC if detected after resection of locally advanced primary or local recurrent rectal cancer.

\section{Methods}

\section{Study population}

The Norwegian Radium Hospital is a tertiary referral center for locally advanced primary and recurrent rectal cancer. Hundred and ninety-one patients with either locally advanced or local recurrent rectal cancer (TNM stage II and III) receiving CRT and subsequent surgery (TME) at the Norwegian Radium Hospital in the period 2000-2006. All patients were of Caucasian origin. Patient's age ranged from 30 to 87 years with a median age of 66 (55\% men, $45 \%$ women). Summary of patient staging can be found in the supplementary material. Surgery was performed a median 56 days after completion of radiotherapy.

\section{Follow-up}

Initially these patients were included in a pilot study where $K R A S$ mutations in exon 1 identified in primary rectal tumors and lavage was reported to be an independent poor prognostic factor for overall survival. [16]. The data is reexamined with extended observation time, and consequently no censored data. The results debate previous findings, of which could have been biased by a large fraction of censored data.

\section{Tumor samples}

Rectal tumor tissue samples harvested during surgery were submerged in an appropriate volume of RNAlater (Qiagen, Valencia, California, USA) After RNAlater removal the samples were frozen at $-80{ }^{\circ} \mathrm{C}$ until DNA extraction. QIAamp DNA Kit (Qiagen, Valencia, California, USA) was used for the DNA extraction, following the manufacturer's instructions. After resection of the tumor, the pelvis was washed with sterile water $200-600 \mathrm{ml}$ (discarded) subsequently followed by $200-600 \mathrm{ml}$ saline water. Two specimens (lavage A and B) of $50 \mathrm{ml}$ lavage fluid were aspirated to centrifuge tubes. Cells were harvested by centrifugation at $1200 \mathrm{G}$ for $10 \mathrm{~min}$ followed by removal of the supernatant. The cell pellets were frozen at $-20{ }^{\circ} \mathrm{C}$ until DNA extractions were performed. QIAamp DNA Kit (Qiagen, Valencia, California, USA) was used for the DNA extraction, following the manufacturer's instructions.

\section{First round PCR}

Amplification of mtDNA was performed using a two step nested PCR protocol to avoid amplification of homologous regions in the nuclear DNA. A set of 5 specific mitochondrial primers were used in the first round PCR to amplify the base pair regions: 15,924201, 16,521-880, 6917-7671, 10,852-11,566, 15,16915,993 , according to the reference mitochondrial build NC_012920.1. Primer sequences are displayed in Table 1. The PCR reaction mixture contained $0.1 \mu \mathrm{l}$ of extracted DNA, $0.8 \mathrm{mM}$ dNTPs $(0.2 \mathrm{mM}$ of each dNTP) (VWR, Oslo, Norway), 1X Thermopol Buffer, $2 \mathrm{mM} \mathrm{MgSO}_{4}, 0.075$ unit Taq/ $\mu \mathrm{l}, 0.15 \mu \mathrm{M}$ of each forward, reverse and fluorescently labeled primer (Integrated DNA Technologies, Leuven, Belgium) and total reaction volume of $10 \mu \mathrm{l}$. The temperature cycling was performed in a Eppendorf Mastercycler ep gradient S (Eppendorf, Hamburg, Germany) with an initial denaturation $94{ }^{\circ} \mathrm{C}$ for $240 \mathrm{~s}$ followed by cycling 38 times under the following conditions, denaturation at $94{ }^{\circ} \mathrm{C}$ for $15 \mathrm{~s}$, annealing for $40 \mathrm{~s}$ with temperature given in Table 1 and elongation at $72{ }^{\circ} \mathrm{C}$ for $150 \mathrm{~s}$.

\section{Capillary electrophoresis}

First round amplification products were verified by capillary electrophoresis in MegaBACE 1000 DNA Analysis System (GE Healthcare Life Sciences, Pittsburgh, PA, USA). Samples were loaded into the capillaries from 96well plates by electro kinetic injection at $161 \mathrm{~V} / \mathrm{cm}$ for $20 \mathrm{~s}$. The temperature of the capillary chamber was set to $27{ }^{\circ} \mathrm{C}$ and electrophoresis was carried out at a constant field of $145 \mathrm{~V} / \mathrm{cm}$.

\section{Second round PCR}

Templates for second round PCR were $0.8 \mu \mathrm{l}$ of a 1:200 dilution (first round PCR in $\mathrm{H}_{2} \mathrm{O}$ ). The templates were dispensed into 96-wells plates with a syringe dispenser (Hydra 96, Robbins Scientific, USA). To each well $10 \mu \mathrm{l}$ reaction mixture was added. The components had a final concentration; 1xThermopol Reaction Buffer with $2 \mathrm{mM}$ $\mathrm{MgSO}_{4}, 0.3 \mu \mathrm{M}$ primers without GC clamp, $0.15 \mu \mathrm{M} 1 /$ 2GC-tailed primer, $0.15 \mu \mathrm{M}$, 6-Carboxyfluorescein-GCclamp, $500 \mu \mathrm{M}$ dNTP, $100 \mu \mathrm{g}$ Bovine Serum Albumine (Sigma-Aldrich, Oslo, Norway) and 0.75 U Cloned Pfu 
Table 1 Primers used in specific mtDNA amplification

\begin{tabular}{|c|c|c|c|c|c|c|}
\hline$\#$ & Start(bp) & End(bp) & Length(bp) & "Forward" primer (5'-3') & "Reverse" primer (5'-3') & $\begin{array}{l}\text { Annealing } \\
\text { temperature }\left({ }^{\circ} \mathrm{C}\right)\end{array}$ \\
\hline 23 & 15,924 & 201 & 846 & ${ }^{\mathrm{a} A A C C G G A G A C G A A A A C C T T T T C}$ & 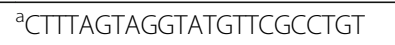 & 51 \\
\hline 1 & 16,521 & 880 & 928 & ${ }^{a}$ CCATAAAGCCTAAATAGCCCACA & ${ }^{\mathrm{a} C C A A C C C T G G G G T T A G T A T A G C T}$ & 54 \\
\hline 10 & 6917 & 7671 & 754 & aTGCTCTGAGCCCTAGGATTCATC & ${ }^{\mathrm{a}} \mathrm{TGAGGGCGTGATCATGAAAGGTG}$ & 55.5 \\
\hline 16 & 10,852 & 11,566 & 714 & ${ }^{a}$ GCCTAATTATTAGCATCATCCCC & ${ }^{\mathrm{a} A T G C C T C A T A G G G A T A G T A C A A G ~}$ & 51 \\
\hline 22 & 15,169 & 15,993 & 824 & ${ }^{\mathrm{a} G A G G G G C C A C A G T A A T T A C A A A C}$ & a'TGGGTGCTAATGGTGGAGTTAAA & 51 \\
\hline
\end{tabular}

a =tail sequence (CGCCCGCCGCGCCCCGCG)

DNA polymerase. Plates were sealed with two strips of electrical tape (Clas Ohlson, Oslo, Norway). The temperature cycling was repeated 30 times; $94{ }^{\circ} \mathrm{C}$ for $15 \mathrm{~s}$, annealing temperature held for $30 \mathrm{~s}$ and extension at $72{ }^{\circ} \mathrm{C}$ for $60 \mathrm{~s}$.

Primer sequences are displayed in Table 2.

\section{Cycling temperature capillary electrophoresis}

6-Carboxyfluorescein labeled PCR products were analyzed in a 96-capillary DNA analyzer MegaBACE 1000. The instrument was modified as previously described to allow for elevated temperature cycling $[17,18]$. The cycling temperature was based on the theoretical melting temperature, for each fragment, calculated by Poland's algorithm in the implementation described by Steger [19]. The separation temperature proposed by the algorithms was adjusted based on the urea concentration in the matrix. The cycling temperature was programmed in the macro. Ini file used by the Instrument Control Manager (ICM) software package (GE Healthcare Life Sciences, Pittsburgh, PA, USA). The injection and running electric fields were as given for the first round amplicons.

\section{Follow up \& statistics}

Patient's survival data for 60 months was obtained from the Norwegian National Health Register. Data analysis was performed using SPSS 23.0 for Windows (SPSS Inc. Chicago IL, USA). The log-rank test assessed the differences in survival between groups and cumulative survival was demonstrated using the Kaplan-Meier plot. $P$-values of less than 0,05 were considered statistically significant.

Table 2 Primers used in second round PCR amplification

\begin{tabular}{|c|c|c|c|c|c|c|}
\hline \# & $\begin{array}{l}\text { Start } \\
(\mathrm{bp})\end{array}$ & $\begin{array}{l}\text { End } \\
\text { (bp) }\end{array}$ & $\begin{array}{l}\text { Template, fragment \# from \# } \\
\text { from }\end{array}$ & "Forwards" primer $\left(5^{\prime}-3^{\prime}\right)$ & "Reverse" primer (5' - 3') & $\begin{array}{l}\text { Annealing } \\
\text { temperature }\left({ }^{\circ} \mathrm{C}\right)\end{array}$ \\
\hline 1 & 16,569 & 25 & 1 & aTGCATGGAGAGCTCCCGTGAGTGG & CCCCTTAAATAAGACATCACGAT & 52 \\
\hline 2 & 42 & 126 & 1 & ${ }^{\mathrm{a} A T T A A C C A C T C A C G G G A G C T C T C}$ & AGGATGAGGCAGGAATCAAAGAC & 55 \\
\hline 4 & 131 & 181 & 1 & ${ }^{\mathrm{a}}$ CACCCTATGTCGCAGTATCTGTC & CACACTITAGTAAGTATGTTCGC & 55 \\
\hline 6 & 483 & 513 & 1 & ${ }^{\mathrm{a}}$ GGGGTTAGCAGCGGTGTGTGTGTG & TCCCACTCCCATACTACTAATCT & 55 \\
\hline 7 & 530 & 633 & 1 & ${ }^{\mathrm{a} T A C C C A G C A C A C A C A C A C C G C T G}$ & CAAACCTATTTGTTAATGGGGTGA & 55 \\
\hline 8 & 673 & 705 & 1 & aTTAGAGGGTGAACTCACTGGAAC & GGTTTGGTCCTAGCCTITCTATT & 58 \\
\hline 82 & 7031 & 7134 & 10 & ${ }^{\mathrm{a} A C G A C A C G T A C T A C G T T G T A G C C}$ & AATATGATAGTGAAATGGATTIT & 52 \\
\hline 84 & 7340 & 7416 & 10 & ${ }^{\mathrm{a} C T T T C T T C C C A C A A C A C T T T ~ C T ~ C ~}$ & TCTCAAATCATGAAAATTATTAAT & 55 \\
\hline 125 & 11,029 & 11,086 & 16 & ${ }^{\mathrm{a}}$ TTAGGAGGGGGGTTGTTAGGGGGT & САТСССТСТACTATITITAAACC & 58 \\
\hline 127 & 11,193 & 11,243 & 16 & ${ }^{\mathrm{a} A C C A G C C A G A A C G C C T G A A C G C A}$ & GGTGTTGTGAGTGTAAATTAGT G & 55 \\
\hline 128 & 11,283 & 11,311 & 16 & 'TGTGCCTGCGTTCAGGCGTTCTGG & TAATCATATTITATATCTTCTTC & 60 \\
\hline 130 & 11,437 & 11,492 & 16 & ${ }^{\mathrm{a}} \mathrm{TTGACCCAGCGATGGGGGCTTCGA}$ & GAGCCAACAACTTAATATGACTA & 55 \\
\hline 176 & 15,201 & 15,257 & 22 & ${ }^{\mathrm{a}}$ AGAATCGTGTGAGGGTGGGACTGT & AGTAATTACAAACTTACTATCCG & 60 \\
\hline 177 & 15,274 & 15,377 & 22 & aAGTAGACAGTCCCACCCTCACAC & GGTGATTTATCGGAATGGGAGG & 60 \\
\hline 178 & 15,394 & 15,448 & 22 & ${ }^{\mathrm{a}}$ CTAGGAATCACCTCCCATTCCGA & TAATGTCATTAAGGAGAGAAGGAA & 55 \\
\hline 181 & 15,761 & 15,864 & 22 & aACCTCCTCATTCTAACCTGAATC & CAGGCCCATTTGAGTATTTGTTT & 55 \\
\hline 184 & 16,080 & 16,130 & 23 & ${ }^{a}$ CAAGTATTGACTCACCCATCAAC & ACAGGTGGTCAAGTATTTATGGTA & 57 \\
\hline 187 & 16,263 & 16,366 & 23 & ${ }^{\mathrm{a} A A C T G C A A C T C C A A A G C C A C C C C}$ & CCCTATCTGAGGGGGGTCATCCAT & 58 \\
\hline
\end{tabular}

a=tail sequence (CCCGCCGCCCCCGCCCGGG)

GC-Clamp = (6FAM-GCGCCCGCCGCGCCCCGCGCCCGTCC CGCCGCCCCCGCCCGGG) 
Area under the curves was measured by use of AcqKnowledge * 4.4.1 Software \& MP150/MP36R in electropherograms displaying low mutant fractions.

\section{Results}

Of 191 locally advanced or local recurrent rectal tumors $72 \%(138 / 191)$ were found positive for at least one mtDNA mutation. Figure 1 displays two representative electropherograms of non mutated and mutated samples. Lavage fluids from these 138 patients were subsequently analyzed for corresponding mtDNA mutations. Forty-five of the lavages were identified with equivalent mtDNA mutations as in the primary tumor, although in different fractions. Figure 2 demonstrates mutations in tumor and in both collections of lavage. Figures 3 and 4 show positive mutant marker only in one of the lavage samples.

By visual inspection of all lavage electropherograms, the mitochondrial mutant fraction in the sample was measured. Based on these data lower limit of detection was calculated to be1\%. For survival analysis, a Kaplan-Meier plot was prepared from patients with locally advanced and local recurrent rectal-cancer with positive and negative IPCC in the lavage fluid (Fig. 5).

Observation time was 60 months for all patients. The log-rank test assessed no significant difference in survival between the positive and negative IPCC for the two groups $(p=0,716$ and $p=0,892)$.

Initially these patients were included in a pilot study where KRAS mutations in exon 1 identified in primary rectal tumors and lavage was reported to be an independent poor prognostic factor for overall survival [16]. Reevaluation of the data with extended time of observation did not validate this assertion. The log-rank test with uncensored data (60 months) gave no significant difference $(p=0,177)$ in survival between positive and negative KRAS mutations in lavage fluid (Fig. 6). When comparing the current patient material with the previous published population [16] no difference in TNM staging was observed (Additional file).

\section{Discussion}

This prospective non-randomized study comprises 191 patients with locally advanced rectal cancer receiving CRT followed by radical surgery.Local recurrence following CRT and TME cannot be explained only by incomplete surgery, vascular or lymphatic invasion [20]. Pelvic IPCC with proliferate or metastatic potential may originate from the primary tumor transmitted either prior to or during surgical procedure and could represent a source of recurrence. [12]. The survival impact of IPCC in lavage harvested after surgery for rectal cancer was investigated. The mtDNA of primary rectal tumors were scanned for mutations. The fragments used are those covering mtDNA hot spots. The mtDNA hot spots were determined by CTCE when scanning $76 \%$ of the genome in 94 tumors of different origin (Manuscript in press). Observing the same mtDNA mutations in primary tumor and lavage supports the presence of IPCC and allowed a simplified experimental protocol. The study population constitutes 138 patients with a positive mtDNA tumor marker and from these a fraction of $33 \%$ $(45 / 138)$ was identified with a corresponding marker in lavage. By detecting the same mtDNA mutation in primary tumor and lavage, was hypothesized to confirm the existence of IPCC. The lavages from 53 tumors without mtDNA mutations were not further analyzed. A yield rate of 33\% was considered sufficient to detect a possible

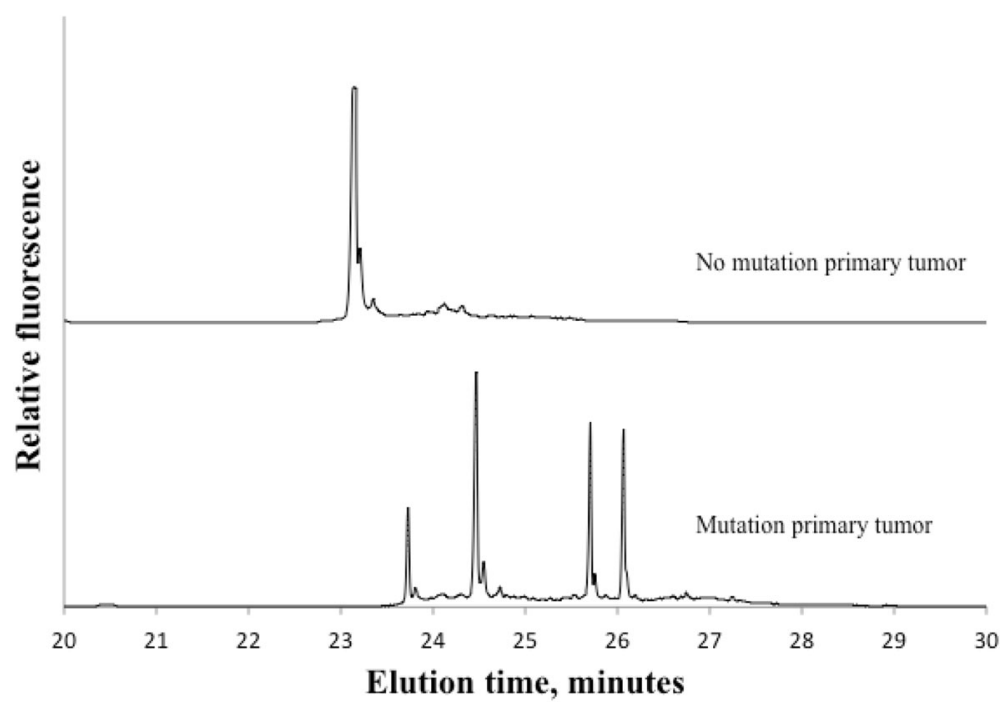

Fig. 1 Electropherogram of primary rectal tumor without mtDNA mutations (top) and primary rectal tumor with mtDNA mutations (lower) 


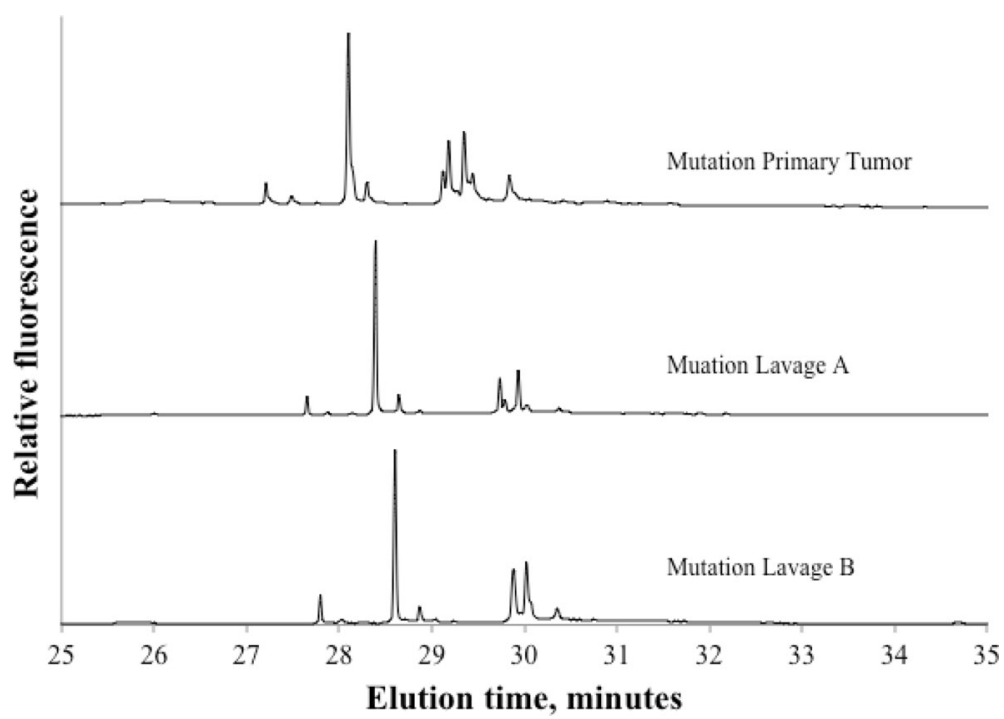

Fig. 2 Electropherograms of mutant positive primary rectal tumor with mtDNA mutations and in corresponding lavage $A$ \& $B$

effect on survival [12]. The steps in IPCC detection include collection procedures and sample treatment, cell separation protocols and chosen biomarkers. Essential to all these methods is the recognition of markers assumed to exclusively represent tumor cells and suspending normal tissue in the examined samples. Due to non-specific labeling, cytology based methods and immunohistochemistry in IPCC detection reports conflicting results [21-23]. Whole genome sequencing is time-consuming, expensive, and impractical for routine analysis and is still left with challenges [24-28]. The combination of a two staged PCR followed by CTCE represents a quantitative, fast and inexpensive method with sufficient throughput to detect mutations in human mtDNA [29]. The standard procedure of peritoneal lavage at the time of study combines sterilized water followed by saline water performed after surgery. Assuming that exfoliated tumor cells will be compromised during exposure to lavage with sterilized water, the tumor cell viability was not tested. The lavage fluid includes circulating DNA generated from bleeding, lymphatic drainage, and tissue damage during surgery and IPCC if present. The detection limit for the method used is in the order of $1 \%$ [29]. With a detection limit at 1\% (sensitivity), the $67 \%$ of lavage fluids without correlating mtDNA mutations, can be considered IPCC deficient. False negative signals may occur as a result of lavage contamination with white blood cells. One $\mathrm{ml}$ of blood contains an average

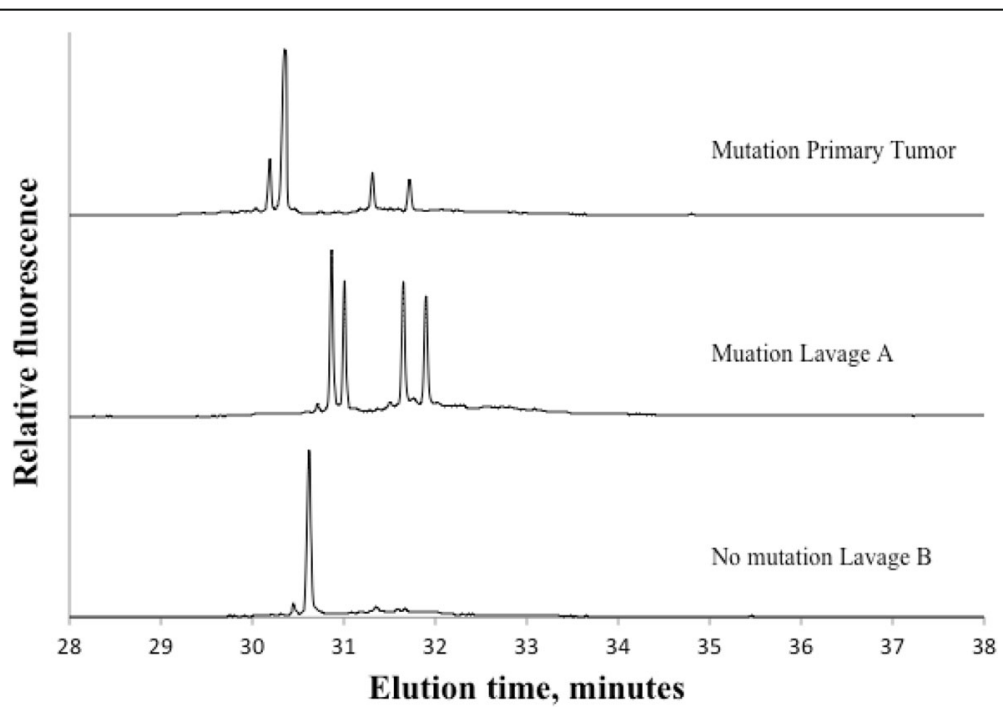

Fig. 3 Electropherograms of primary rectal tumor with mtDNA mutations and mtDNA mutations in lavage A, but not in lavage B 


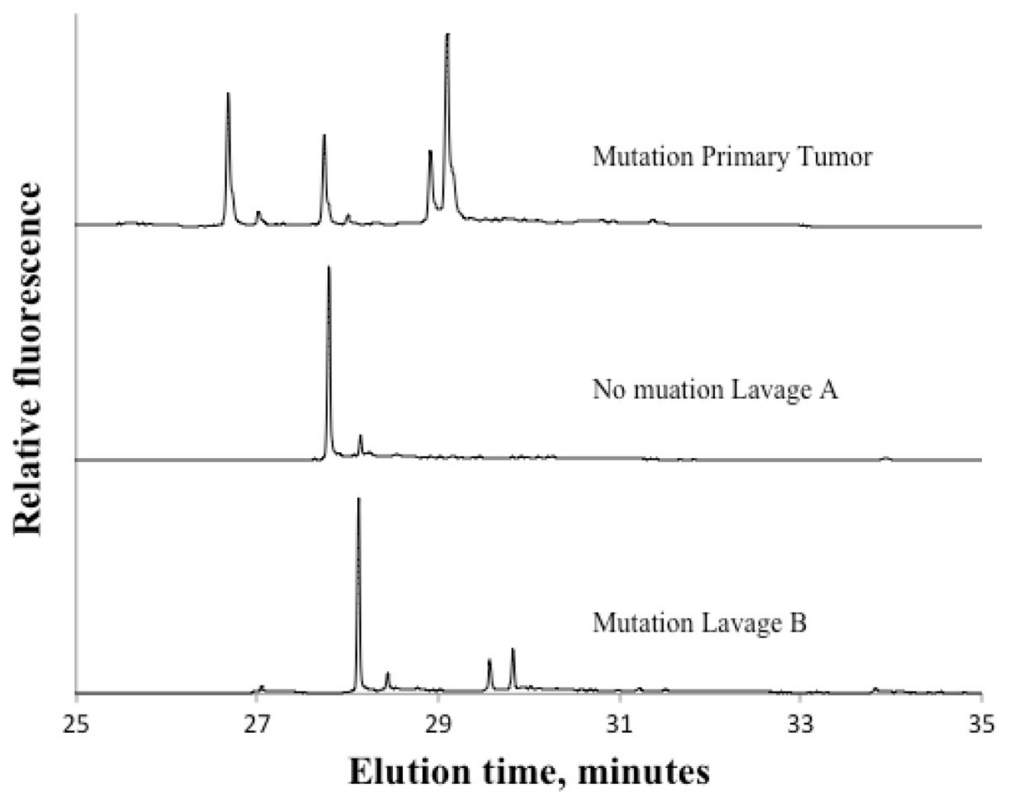

Fig. 4 Electropherograms of primary rectal tumor with mtDNA mutations and without mtDNA mutations in lavage $A$, but with mutation in lavage $B$

of $5 \times 10^{6}$ white blood cells. Consequently inevitable surgical bleeding may dilute the IPCC signal below detection limit. The probability of a sub population of cells to acquire mutations as observed in the primary tumor is less than 1:1000 (unpublished data), thus justifying the hypothesis that the IPCC signal is derived from the primary tumor. Observing coexisting mtDNA mutations in primary tumor and lavage identifies one tumor lineage. However, all possible tumor lineages are not necessarily identified. When analyzing tumor and lavage, four possible analytical outcomes are to be expected. First, detecting positive marker in tumor and lavage (Figs. 2, 3 and 4). This observation is the only combination confirming the presence of IPCC. Second and third, detecting positive marker in tumor or lavage, while the respectively lavage and tumor are negative for the marker. These outcomes do not exclude IPCC if the tumor lineage is devoid of the mtDNA mutation examined or below detection limit of the assay. Fourth, when tumor and lavage does not contain the marker, possible IPCC cannot be excluded. Consequently, 75\% of the assay information is non-informative concerning IPCC status. Hence, a prerequisite for analyzing lavage samples was positive mtDNA mutations detected in

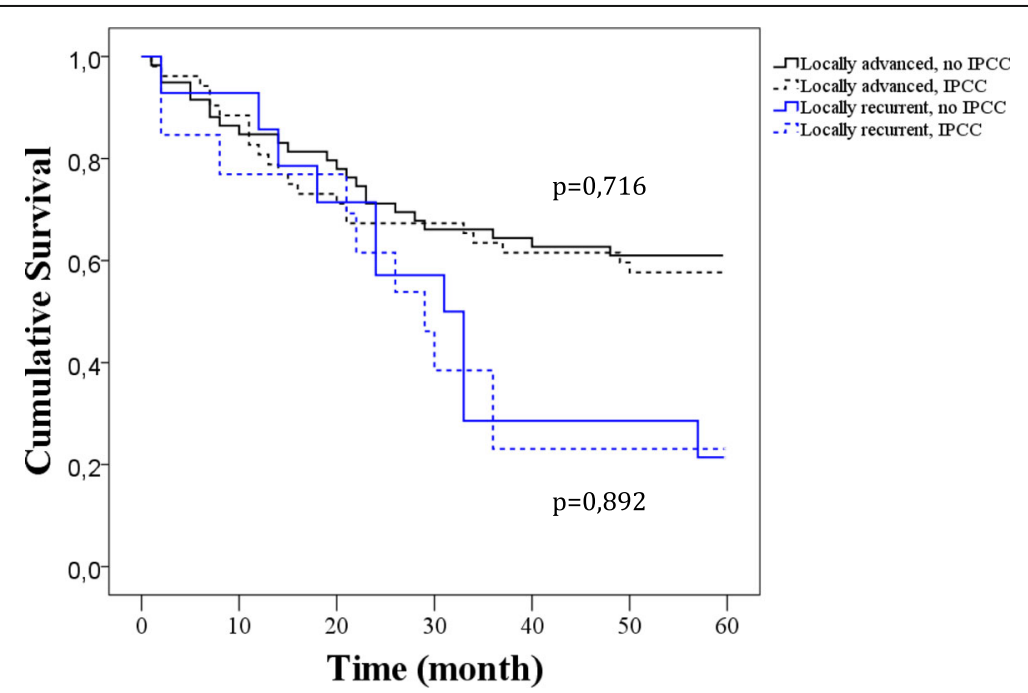

Fig. 5 Kaplan-Meier plot. Survival analysis, calculated from patients with locally advanced and locally recurrent rectal cancer, having positive IPCC or negative IPCC. No censored data 


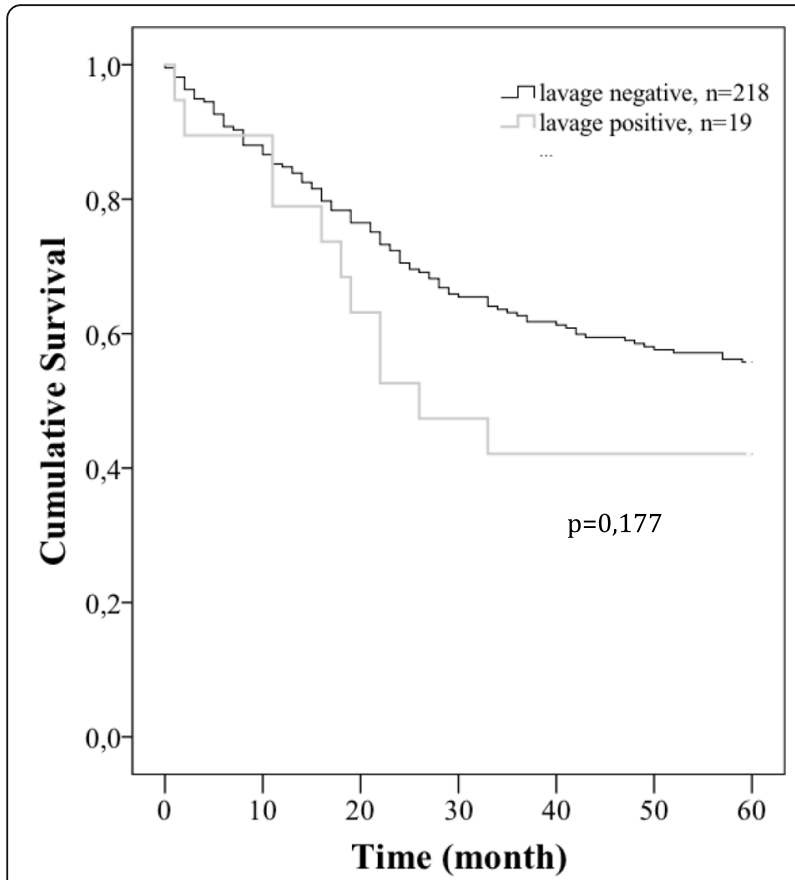

Fig. 6 Kaplan-Meier plot. Survival analysis, calculated from patients with KRAS mutations positive vs. KRAS mutations negative in lavage fluid. No censored data $(P=0,177)$

primary tumors. The frequency of primary rectal tumors with mtDNA mutation in hot-spot fragments was found to be $72 \%$. From these, $33 \%$ had the same mtDNA mutations in the primary tumor and lavage, and was interpreted to represent IPCC. The ambition of pelvic exposure to sterilized water after surgery is to compromise the viability of possible remnants with proliferate or metastatic potential. The mtDNA molecular signal does not discriminate IPCC from their residues. A yield rate of $33 \%$ of IPCC detected exceeds upper limits of previous reports [12]. The survival analysis, comparing patients with positive or negative IPCC in lavage fluid disclosed no significant difference on survival (Fig. 5). This is in contrast with former report on the same patient material using KRAS mutations as IPCC marker [16]. However, at the time of the previous study, a large fraction of the population was censored, as the observation time was not completed. In accordance with the authors of the previous article [16], the data was re-evaluated, with all patients having their observation period of 60 month complete, and thus no censored data. This reevaluation did not confirm the original observation. Detection of KRAS mutation in lavage fluid have no statistically significant effect on survival (Fig. 6). This observation is in concordance with the lead author of the original research article (cowriting this paper) and will be conveyed to the publisher (BMC Cancer).

\section{Conclusion}

Mutations in mtDNA can be detected in locally advanced or local recurrent rectal tumors and followed in exfoliated tumor cells with a detection limit of $1 \%$.

The impact of finding the coexisting mutation in primary tumor and lavage disclosed no prognostic significance on survival.

KRAS mutations identified in locally advanced or local recurrent rectal tumors and lavage formerly labeled to be an independent poor prognostic factor on overall survival was not validated.

\section{Abbreviations \\ CRT: Chemo radiotherapy; CTCE: Cycling temperature capillary electrophoresis; IPCC: Intraperitoneal free cancer cells; MtDNA: Mitochondrial DNA; PCR: Polymerase chain reaction; TME: Total mesorectal excision \\ Funding \\ This work received financial support from the Torsteds legacy (Oslo, Norway). \\ Availability of data and materials \\ The data that support the findings of this study are available from the Norwegian National Health Register but restrictions apply to the availability of these data, which were used under license for the current study, and so are not publicly available. The reference mitochondrial sequence NC_012920.1.were obtained from http://www.ncbi.nlm.nih.gov/nuccore/ NC_012920.1 \\ Data concerning mtDNA mutations analysis and sequencing data are however available from the authors upon request.}

\section{Authors' contributions}

CA performed PCR and CTCE; PR designed the primers, tested the PCR and optimized the PCR conditions. KEG collected samples, ATK was responsible for bio banking and DNA extraction. POE participated in the design of the study. All authors contributed in the writing the manuscript and have read and approved the final version.

\section{Competing interests}

The authors have declared no conflict of interest.

Consent for publication

Not applicable.

Ethics approval and consent to participate

Application (No. 2015/2350) was approved by the Regional Committee for Medical and Health Ethics of South-East Norway 2016-02-15 and followed the Declaration of Helsinki guidelines. Written informed consent was required for participation.

\section{Publisher's Note}

Springer Nature remains neutral with regard to jurisdictional claims in published maps and institutional affiliations.

\section{Author details}

'Department of Tumor Biology, Institute for Cancer Research, The Norwegian Radium Hospital, Oslo, Norway. ${ }^{2}$ Chaire de Statistique Appliques, Section de Mathematiques, EPFL, Lausanne, Switzerland.

Received: 7 October 2016 Accepted: 17 May 2017

Published online: 07 June 2017

\section{References}

1. Cancer in Norway 2014 - Cancer incidence, mortality, survival and prevalence in Norway. Oslo:Cancer. https://www.kreftregisteret.no/ globalassets/cancer-in-norway/2014/cin_2014.pdf. Registry of Norway, 2015.

2. Valentini V, Beets-Tan R, Borras JM, Krivokapic Z, Leer JW, Pahlman L, et al. Evidence and research in rectal cancer. Radiother Oncol. 2008;87(3):449-74. 
3. Kusters M, Marijnen CA, van de Velde CJ, Rutten HJ, Lahaye MJ, Kim JH, et al. Patterns of local recurrence in rectal cancer; a study of the Dutch TME trial. Eur J Surg Oncol. 2010;36(5):470-6.

4. Segelman J, Granath F, Holm T, Machado M, Mahteme H, Martling A. Incidence, prevalence and risk factors for peritoneal carcinomatosis from colorectal cancer. Br. J. Surg. 2012:99(5):699-705.

5. Lowe $\mathrm{E}, \mathrm{McKenna} \mathrm{H}$. Peritoneal washing cytology: a retrospective analysis of 175 gynaecological patients. Aust N Z J Obstet Gynaecol. 1989;29(1):55-61.

6. Ziselman EM, Harkavy SE, Hogan M, West W, Atkinson B. Peritoneal washing cytology. Uses and diagnostic criteria in gynecologic neoplasms. Acta Cytol. 1984;28(2):105-10

7. Colgan TJ, Boerner SL, Murphy J, Cole DE, Narod S, Rosen B. Peritoneal lavage cytology: an assessment of its value during prophylactic oophorectomy. Gynecol Oncol. 2002;85(3):397-403.

8. Nath J, Moorthy K, Taniere P, Hallissey M, Alderson D. Peritoneal lavage cytology in patients with oesophagogastric adenocarcinoma. Br. J. Surg 2008;95(6):721-6.

9. litsuka Y, Shiota S, Matsui T, Murata Y, Kimura A, Koga S. Relationship between the cytologic characteristics of intraperitoneal free cancer cells and the prognosis in patients with gastric cancer. Acta Cytol. 1990;34(3):437-42.

10. Boku T, Nakane Y, Minoura T, Takada H, Yamamura M, Hioki K, et al. Prognostic significance of serosal invasion and free intraperitoneal cancer cells in gastric cancer. Br. J. Surg. 1990;77(4):436-9.

11. Bonenkamp JJ, Songun I, Hermans J, van de Velde CJ. Prognostic value of positive cytology findings from abdominal washings in patients with gastric cancer. Br. J. Surg. 1996;83(5):672-4.

12. Passot G, Mohkam K, Cotte E, Glehen O. Intra-operative peritoneal lavage for colorectal cancer. World J Gastroenterol. 2014;20(8):1935-9.

13. Sibio S, Fiorani C, Stolfi C, Divizia A, Pezzuto R, Montagnese F, et al. Detection methods and clinical significance of free peritoneal tumor cells found during colorectal cancer surgery. World JGastrointest Surg. 2015;7(9):178-84.

14. Skipper D, Cooper AJ, Marston JE, Taylor I. Exfoliated cells and in vitro growth in colorectal cancer. Br. J. Surg. 1987;74(11):1049-52.

15. Umpleby HC, Fermor B, Symes MO, Williamson RC. Viability of exfoliated colorectal carcinoma cells. Br J Surg. 1984;71(9):659-63.

16. Kristensen AT, Wiig JN, Larsen SG, Giercksky KE, Ekstrom PO. Molecular detection ( $k$-ras) of exfoliated tumour cells in the pelvis is a prognostic factor after resection of rectal cancer? BMC Cancer. 2008;8:213.

17. Ekstrom PO, Bjorheim J, Thilly WG. Technology to accelerate pangenomic scanning for unknown point mutations in exonic sequences: cycling temperature capillary electrophoresis (CTCE). BMC Genet. 2007;8:54.

18. Ekstrom PO, Khrapko K, Li-Sucholeiki XC, Hunter IW, Thilly WG. Analysis of mutational spectra by denaturing capillary electrophoresis. Nat Protoc. 2008:3(7):1153-66.

19. Steger $\mathrm{G}$. Thermal denaturation of double-stranded nucleic acids: prediction of temperatures critical for gradient gel electrophoresis and polymerase chain reaction. Nucleic Acids Res. 1994;22(14):2760-8.

20. Wu JS, Fazio W. Management of rectal cancer. J Gastrointest Surg. 2004;8(2):139-49.

21. Hase K, Ueno H, Kuranaga N, Utsunomiya K, Kanabe S, Mochizuki H. Intraperitoneal exfoliated cancer cells in patients with colorectal cancer. Dis Colon Rectum. 1998;41(9):1134-40.

22. Vogel P, Ruschoff J, Kummel S, Zirngibl H, Hofstadter F, Hohenberger W, Jauch KW: Prognostic value of microscopic peritoneal dissemination: comparison between colon and gastric cancer. Dis Colon Rectum 2000, 43(1):92-100.

23. Kanellos I, Demetriades H, Zintzaras E, Mandrali A, Mantzoros I, Betsis D. Incidence and prognostic value of positive peritoneal cytology in colorectal cancer. Dis Colon Rectum. 2003;46(4):535-9.

24. Salas A, Yao YG, Macaulay V, Vega A, Carracedo A, Bandelt HJ. A critical reassessment of the role of mitochondria in tumorigenesis. PLoS Med. 2005;2(11):e296

25. Roach JC, Glusman G, Smit AF, Huff CD, Hubley R, Shannon PT, et al. Analysis of genetic inheritance in a family quartet by whole-genome sequencing. Science (New York, NY). 2010:328(5978):636-9.

26. Mardis ER. Next-generation DNA sequencing methods. Annu Rev Genomics Hum Genet. 2008:9:387-402.

27. Gundry M, Vijg J. Direct mutation analysis by high-throughput sequencing: from germline to low-abundant, somatic variants. Mutat Res. 2012;729(1-2):1-15.

28. Wall JD, Tang LF, Zerbe B, Kvale MN, Kwok PY, Schaefer C, et al. Estimating genotype error rates from high-coverage next-generation sequence data. Genome Res. 2014;24(11):1734-9.
29. Refinetti P, Morgenthaler S, Ekstrom PO. Cycling temperature capillary electrophoresis: a quantitative, fast and inexpensive method to detect mutations in mixed populations of human mitochondrial DNA Mitochondrion. 2016:29:65-74.

\section{Submit your next manuscript to BioMed Central and we will help you at every step:}

- We accept pre-submission inquiries

- Our selector tool helps you to find the most relevant journal

- We provide round the clock customer support

- Convenient online submission

- Thorough peer review

- Inclusion in PubMed and all major indexing services

- Maximum visibility for your research

Submit your manuscript at www.biomedcentral.com/submit 